\title{
Self-identity threat and resistance to change: Evidence from regular travel behaviour
}

\author{
Abstract \\ Despite widespread acceptance of the need to change individual behaviour towards \\ sustainability, resistance to change remains a continuing challenge. Past behaviour or habit, \\ and psychological reactance, have been explored as components of resistance. Growing \\ evidence for the influence of self-identity on behaviour suggests self-identity as a further \\ factor. The current study draws on Identity Process Theory (Breakwell, G.M., 1986, Coping \\ with threatened identities. London: Methuen) to propose that threat to self-identity \\ contributes to resistance to change, over and above the influence of past behaviour. Using \\ travel-related vignettes to trigger threat, a study with 295 working parents in England found \\ evidence supporting the relationship between self-identity threat and resistance to change \\ travel behaviour, controlling for past behaviour. The findings further suggest identity threat \\ as an alternative theoretical perspective on reactance. The results build theoretical \\ understanding of resistance as a barrier to behaviour change. The application of an identity \\ theory to understanding resistance is argued to add potentially new ways to encourage change \\ towards sustainable behaviour. In addition, the findings suggest rich avenues for future \\ research on the theoretical and empirical implications of the relationship of identities and \\ sustainable behaviours.
}

Keywords: self-identity; identity threat; resistance to change; psychological reactance; travel behaviour; sustainable behaviour 


\section{Introduction}

Behaviour change by individuals is important for both preventing the acceleration, and reducing the impacts, of climate change (Christie, 2010). Perceived levels of cynicism and mistrust in climate science have increased somewhat in recent times (Spence, Venables, Pidgeon, Poortinga, \& Demski, 2010). Nevertheless, the majority of the population in the UK accept the potential impacts of climate change, are concerned about it, and indicate that they are prepared to reduce their energy use to aid mitigation of the risks (Carrington, 2011). However, behaviour patterns continue to show increased demands for energy use rather than the reductions suggested in public opinion surveys (Stoll-Kleemann, O'Riordan, \& Jaeger, 2001; Whitmarsh, 2009). A pertinent example is the increase by $8 \%$ between 1998 and 2008 of the distance travelled by car (DfT, 2009). Given the evidence for personal travel as the highest contributor of UK household greenhouse gas emissions after domestic energy (Druckman \& Jackson, 2009), the failure to change travel behaviour merits further investigation and travel behaviour is therefore the focus of the current study.

The mismatch between responses to surveys of values, attitudes or beliefs and actual behaviour has been termed the 'value action gap' and has been widely documented in relation to a range of sustainable behaviours (Chung \& Leung, 2007; Flynn, Bellaby, \& Ricci, 2009). Amongst the many factors postulated to contribute to the gap are past behaviour and psychological reactance. We briefly review the evidence for past behaviour and reactance as contributing to the broader construct of resistance to change, and argue that threat to identity is a further contributory factor.

Resistance to change is a psychological phenomenon of long-standing interest in many applied branches of psychology, from health to organisational psychology. Resistance to change has been seen as an almost inevitable response to required change (Dent \& Goldberg, 1999), a universal tendency (Rogers, 1965), and a personality trait (Oreg, 2003). 
Research approaches have positioned it as a barrier to overcome (Albarracin, Durantini, Earl, Gunnoe, \& Leeper, 2008) or, on the contrary, as a resource with which to work (Ford \& Ford, 2010).

Past behaviour has been acknowledged as a predictor of future action (Ajzen, 1991), with empirical support for its contribution over and above attitudes and intentions (Ouellette \& Wood, 1998). Behaviour that is experienced as successful is likely to be repeated (Aarts, Verplanken, \& van Knippenberg, 1998), and may lead to habitual patterns. Although repeated past behaviour and habit have been used synonymously (e.g. Verplanken, Aarts, \& Van Knippenberg, 1997), some scholars differentiate between the two concepts. Habit has been defined as repeated past behaviour that is additionally goal-oriented and automatic (Aarts et al, 1998; Ouellette \& Wood, 1998). Further, the non-deliberative nature of habit (Gärling \& Axhausen, 2003) may make appeals to reason or judgement ineffective. In this paper, while acknowledging the likely overlap with habit, we use past behaviour as the broader construct, of repeated behaviour without a necessary constraint of goal-orientation. Disrupting repeated or habitual behaviour can be difficult, thus repeated past behaviour may be a component of resistance to change (Stoll-Kleemann, et al., 2001).

However, resistance to change has been argued to result from psychological factors more complex than behaviour patterns (Bovey \& Hede, 2001). Psychological Reactance Theory (Brehm, 1966) proposes that resistance is an aspect of counteractive behaviour elicited by a perceived threat to freedom. Brehm's theory argues that individuals maintain the belief that they are free to engage in a range of behaviours, and that reactance is experienced when a behaviour believed to be 'free' is prevented or threatened with prevention (ibid.). Individuals may vary on trait reactance, that is, a generalised tendency to non-compliance or to resist influence and advice from others (Pavey \& Sparks, 2009). Distinct from trait reactance, state reactance is defined as a motivation aimed at restoring behavioural freedom. 
The strength of (state) reactance derives from the importance of the threatened freedom in satisfying important needs. Reactance Theory (Brehm, 1966) however does not define these needs. Are such needs physiological, such as hunger, psychological, such as self-esteem, or both? Do they relate to existing classifications of needs, such as those of Maslow (1943) or Sheldon and colleagues (2001)? Needs may be seen as prerequisite conditions for initiation of the reactance process. As such, their lack of definition is, we suggest, a theoretical weakness that makes it difficult to conceptualise 'freedom' and therefore reactance. Without clear conceptualisations, it becomes problematic to relate Psychological Reactance Theory to other theories of psychological processes, and to specify conditions for testing the theory. Nonetheless, some theoretical relationships have been suggested. Brehm and Brehm (1981) proposed that a sense of competence or self-efficacy is a pre-requisite for reactance to occur. Hellman and McMillin (1997) linked reactance to self-esteem. Thus state reactance may overlap theoretically with, and offer a partial explication of, more general threats to identity.

Empirical work has begun to establish self-identity as an influence on behaviour (Falomir \& Invernizzi, 1999; Gray, Amos, \& Currie, 1997; Nuttbrock \& Freudiger, 1991; Oyserman, Fryberg, \& Yoder, 2007). Indeed, Sparks and colleagues (Sparks \& Guthrie, 1998; Sparks \& Shepherd, 1992) found evidence for self-identity as a predictor of intention, and thus of behaviour, over and above the factors comprising the Theory of Reasoned Action (Fishbein \& Ajzen, 1975) and the Theory of Planned Behaviour (Ajzen, 1991). They argued that self-identity has a direct relationship with intention, contrary to their initial expectation that self-identity would exert influence via attitudes. Other findings point to the involvement of self-identity in resistance to change behaviour. Hansen, Winzeler and Topolinski (2010) found that participants who rated smoking as important to their self-esteem were, perversely, more likely to rate smoking as positive after exposure to health warnings such as "Smoking Kills”. Liberman and Chaiken (1992) demonstrated that personal relevance heightened 
defensiveness in response to threatening messages, and that defensiveness may be triggered by threats to important parts of self-image (GinerSorolla \& Chaiken, 1997; Tesser \& Cornell, 1991). Theoretical perspectives on self-identity too have argued that identities guide actions chosen or resisted (e.g. Stryker, 1987). In particular, Identity Process Theory (IPT; Breakwell, 1986) proposed mechanisms by which threats to self-identity could result in resistance to change behaviour.

Breakwell's (1986) Identity Process Theory defines a theoretical framework which specifies structure and processes: the self-concept is structured along the two dimensions of content and value, and the processes of assimilation/accommodation and evaluation create and modify content and value. Content is added through experience, including reflection on experience, and each element of content is attributed a value, on a bipolar spectrum from negative to positive. Thus an experience of losing one's job, for example, may cause the generation of additional content in the self: 'I am someone who is unemployed', 'I am free to train for a new career', with associated values of negative and positive valence. Thus Identity Process Theory provides an extensive theoretical explication of the self, encompassing how the self develops over time and how its content and associated value emerge from context, including social context, and experience. Many of the elements of identity discussed in the identity literature, for example values (Schwartz, 1992), personal goals (Emmons, 1986) and narratives (McAdams, 1995) may be understood as elements of the content of self-identity. Alternative perspectives on identity which emphasise social roles, such as Stryker's sociological role theory (1987), can be seen as compatible with IPT, with role identities ${ }^{1}$ also forming part of content. It is IPT's consistency with other perspectives on identity, the potential to incorporate other theoretical views within its framework and, in particular, its

\footnotetext{
${ }^{1}$ The term 'role identity' is used to differentiate between the sociological role identities described by Stryker and others, and 'self-identity', or the more general construct which relates to an overall self-concept.
} 
extensive elaboration of the processes of threat that led to our application of IPT in the current study.

Having defined self-identity, discussion now focuses on ancillary processes proposed by the theory which guided our research. Identity Process Theory explains threat with respect to its fundamental tenet that the self operates in compliance with specific guiding principles. Threat is experienced if the guiding principles of self-esteem, self-efficacy, continuity (of the self through time) and distinctiveness (a positive sense of uniqueness) are undermined (Breakwell, 1986, 1988). Thus threat is understood as an attack or potential attack on one or more of self-esteem, self-efficacy, continuity or distinctiveness. The critical contribution of IPT is in its proposal that threat invokes particular psychological processes which function as coping strategies. A range of strategies for coping with threat is potentially available and the strategies may be categorised as deflecting or accepting. Deflection strategies include denial of the existence of a threat, reconstrual of its meaning, and negativism, or confronting the source of threat. Acceptance strategies include re-evaluation of principles and fundamental identity change. IPT can be seen to build on the extensive literature on self-esteem threat, a literature which also suggests that the experience of threat triggers cognitive and/or behavioural adjustment responses. However, IPT extends self-esteem theories by proposing motivations and guiding principles beyond self-esteem, supported by theoretical argument and empirical evidence for a broader perspective on threat (Abrams, 1988; Sedikides \& Strube, 1997; Vignoles, Chryssochoou, \& Breakwell, 2002; Vignoles, Regalia, Manzi, Golledge, \& Scabini, 2006). Building from Breakwell's theory, it can be suggested that deflection strategies, in defence of the self under threat, may result in resistance to change.

It is possible then to suggest that identity threat may offer an alternative theoretical perspective on the phenomenon of reactance. A threat to freedom, as described in psychological reactance theory, appears conceptually similar to a threat to self-efficacy. A 
sense of self-efficacy encompasses feeling not only competent but also in control of one's life and context. A threat to freedom implies curtailment of control and limitations on autonomy, and a consequent impact on self-esteem can be suggested. A threat to freedom may also overlap conceptually with threats to continuity and distinctiveness. Removal of a previouslyheld freedom will challenge the individual's sense of continuity of self. Boundaries to action may prevent the individual from behaviour which expresses aspects of distinctive uniqueness. Harnessing sociological role theory, it is possible to suggest that a threat to freedom threatens an identity as an independent and autonomous individual, an identity which is likely to be both highly central and highly salient in most adults (Ryan \& Deci, 2000).

Thus we propose that identity threat may provide an alternative, and theoretically richer, framework than reactance for examining resistance to change. As an exploratory study, the current research represents a novel attempt to link identity theories with resistance, to position resistance in a theoretical framework which proposes underlying psychological processes, and to establish preliminary empirical evidence for the relationship between identity threat and resistance in the domain of travel behaviour.

Psychological reactance was measured alongside identity threat. In Brehm’s (1966) original exposition of reactance theory, the power of the source of threat is posited as a major predictor of reactance. The importance of the relative power of source has been confirmed empirically (Invernizzi, Falomir-Pichastor, Munoz-Rojas, \& Mugny, 2003), thus we measured state reactance as both a threat to freedom and the perceived power of the source of threat. In addition, trait reactance was measured as a control.

Identity threat was measured based on Breakwell (1986) as described in Section 2.4 below. To facilitate the invocation of threat in the study, we drew on role identities previously established. An earlier study (Murtagh, Gatersleben, \& Uzzell, 2012) linked role identities to travel mode choice and demonstrated that identities such as driver, public- 
transport user, worker and parent were related to travel behaviour. Of these role identities, we chose two to investigate in the current study: driver and parent. Although other means of triggering identity threat could be explored, we chose role identities as specific domains within identity content at which threat could be targeted. The norms and expectations of a parent identity are relatively clear: there is some societal consensus on what constitutes a 'good parent' (Rosenberg, 1979). The norms and expectations of a driver identity are less clear. The choice of contrasting role identities offered the opportunity to investigate if, and how, threat to different role identities may influence resistance to change. In the absence of empirical findings to suggest differences between role identities in how threat would relate to resistance to change, we postulated that threat to either would contribute to resistance. As identity importance or centrality varies between identities (Vignoles, et al., 2002), we controlled for centrality and, as identity threat may cause negative emotions, we also controlled for affect. Our hypotheses were:

H1: Self-identity threat is related to resistance to change travel behaviour.

H2: Self-identity threat contributes to resistance to change, over and above past travel behaviour.

\section{Method}

The study design used vignettes (short descriptive scenarios) and required participants to imagine themselves in the scenarios depicted. Participants' perception of the level of threat to self-identity was measured. In addition, a vignette design allowed control of individuals' personal circumstances: instead of seeking to capture the complexity of individuals' travel mode choices (distance to work, school, public transport, etc.), relatively simple travel vignettes were presented to all participants within each group. 


\subsection{Participants}

The vignettes were based in urban or suburban settings, and referred to travel to work, school or other local journeys. Target participants therefore were in employment, were parents of primary school-age children, owned a car and were recruited in urban and suburban locations across England. Participants had a personal income at or over the national average ( $£ 25,000$, approximately $€ 30,000)$ per annum: disposable income may relate to perceptions of choices in travel mode (Anable, 2005). A national team of field researchers collected the data in July 2010, by 'cold-calling' to random households in locations with socioeconomic categories of skilled manual, clerical, junior and intermediate occupations. Response rate was estimated at $10 \%$.

Table 1 presents the demographic data. The sample was in line with national population estimates of $88 \%$ White or White British (ONS, 2010), although with limited representation of other ethnic groups.

\subsection{Procedure}

The study comprised a paper questionnaire, completed by participants in their homes. Two forms of questionnaire were used, one of which presented vignettes relevant to parents, the other of which presented vignettes relevant to motorists. The formats of both were identical. Participants were randomly allocated one or other form of questionnaire. An initial short priming task required the participant to write between three and six sentences on how being a parent or a motorist was important to them. This was to ensure that the target identity was salient. Demographic details, baseline measures of emotion, future intentions regarding travel mode, measures of identity centrality, trait reactance and past transport behaviour were requested. The participants was asked to read each one of eight vignettes and answer items for each on intention to change travel behaviour and the perceived levels of threat to identity and freedom posed by the vignette. The study required about 20 minutes to complete. No 
incentives were offered. Participants were assured of anonymity, confidentiality and the right to opt out.

Table 1 Demographic data

\begin{tabular}{|c|c|c|c|}
\hline & $\begin{array}{l}\text { Total } \\
\text { Sample } \\
(\mathrm{N}=299)\end{array}$ & $\begin{array}{l}\text { Parent } \\
\text { Subgroup } \\
(\mathrm{N}=150)\end{array}$ & $\begin{array}{l}\text { Motorist } \\
\text { Subgroup } \\
(\mathrm{N}=149)\end{array}$ \\
\hline \multicolumn{4}{|l|}{ Gender } \\
\hline Female & $62 \%$ & $67 \%$ & $57 \%$ \\
\hline Male & $38 \%$ & $33 \%$ & $43 \%$ \\
\hline \multicolumn{4}{|l|}{ Age } \\
\hline Mean & 40.19 & 37.14 & 43.18 \\
\hline SD & 9.43 & 6.94 & 10.56 \\
\hline Range & $23-69$ & $23-56$ & $25-69$ \\
\hline \multicolumn{4}{|l|}{ Ethnicity } \\
\hline White/White British & $90.6 \%$ & $93.3 \%$ & $87.9 \%$ \\
\hline Asian/Asian British & $3.3 \%$ & $4.0 \%$ & $2.7 \%$ \\
\hline Black/Black British & $3.7 \%$ & $2.7 \%$ & $4.7 \%$ \\
\hline Mixed & $2 \%$ & $0 \%$ & $4.0 \%$ \\
\hline Other & $0.3 \%$ & $0 \%$ & $0.7 \%$ \\
\hline
\end{tabular}

2.3 Material

All vignettes described a travel-related scenario (see Appendix for examples). Four vignettes were designed to threaten the target identity (either motorist or parent) and four were designed as neutral with respect to identity threat. Brehm (1966) had proposed that the experience of a threat to freedom was influenced by the source: the more powerful the source 
of the threat, the greater the experience of threat. Invernizzi and colleagues (2003) showed empirically that the level of threat can depend on the source, so the source of threat was controlled across the vignettes. Of the threat vignettes, two were designed to include a powerful figure or institution as the instigator of change to travel behaviour, for example, the government or local authority. The remaining two threat vignettes included a non-powerful instigator of change, for example, other parents. The neutral vignettes also included an even split of powerful and non-powerful instigators of change. The vignettes were balanced on length, and on the cost, time and convenience required to make a change and this was verified independently by twelve post-graduate students.

\subsection{Measures}

\section{Resistance to change}

Using intention as a proxy for behaviour in line with the Theory of Reasoned Action (Ajzen \& Fishbein, 1980; Fishbein \& Ajzen, 1975) and Theory of Planned Behaviour (Ajzen, 1985), resistance to change travel behaviour was measured as the inverse of intention to change, with a single item for each of the eight vignettes. The item was phrased in positive terms: "How likely is it that you would intend to change your behaviour?", worded appropriately for each vignette, for example "How likely is it that you would intend to have your child walk to school more often?" [Parent Vignette 2]. The response was on a six-point scale, anchored at "Very unlikely" (scored as 1) and "Very likely" (scored at 6). Resistance to change was calculated as the reverse scores, for example, a response of ' 1 ' on the item represented a score of ' 6 ' for resistance to change.

\section{Identity threat}

Threat to identity was measured with 4 items for each of the 8 vignettes. One item each assessed the threat to self-esteem, generalised self-efficacy, continuity and distinctiveness, that is, the four guiding principles of the self-concept defined in Identity 
Process Theory (Breakwell, 1986, 1988). The items were "It undermines my sense of selfworth", "It makes me feel less competent", "I would have to change who I am", and "It makes me feel less unique as a person". Each item was rated on a six-point scale, anchored at "Very unlikely" (scored as 1) and "Very likely" (scored at 6) and identity threat was the mean of the 4 items. Cronbach alpha was calculated for each vignette and all scores were above 0.9 .

Psychological reactance

Psychological reactance was measured with two items per vignette. One item assessed the perceived threat to freedom: "It threatens my freedom". The other item assessed the perception of power to enforce change by the instigator of change in the vignette, for example, "The council has the power to make me change what I do" (Parent vignette 1). Reactance was calculated as the mean of the two items.

\section{Past travel behaviour}

Past or habitual travel behaviour was measured with one question covering four items: 'In general, how often do you do the following for local journeys? Cycle / Use local bus / Walk / Take a train, tube or tram?', with a fifth item on the Parent questionnaire: 'Allow your children to walk (accompanied or unaccompanied)?'. The items were anchored at 1 'Rarely or never' to 5 'Very often'. These items were used separately in the analysis.

\section{Control variables}

\section{State emotion}

Positive and negative emotions were measured before the participant had reviewed the vignettes. A shortened version of the PANAS scale (Watson, Clark, \& Tellegen, 1988) was used. Cronbach alpha was .86 and .91 for positive and negative affect respectively. 


\section{Trait reactance}

Trait reactance is defined as a characteristic tendency to react negatively or to reject new information or suggestions. It was measured using the Hong Psychological Reactance Scale (Hong \& Faedda, 1996). The scale showed good reliability $(\alpha=.83)$.

\section{Identity centrality}

Identity centrality was measured using one item based on Vignoles et al. (2006):

"Being a parent/driver is an important part of defining who I am", anchored at 1 (Not at all true) to 6 (Very true).

\section{Baseline intention to change}

To control for previous intention to change travel behaviour, one item was used: "I intend to drive less in the future", anchored at 1 (Strongly disagree) to 6 (Strongly agree). This was embedded with seven similar distracter items which referred to intending to get fitter, lose weight, cycle and spend more time outdoors, and was asked early in the questionnaire before the vignettes were presented.

\subsection{Data analysis}

The data were inspected and tested for univariate and multivariate outliers. One case was excluded because of age given as 12 years; one case was excluded as a multivariate outlier identified using Mahalanobis' distances; and three cases were excluded as univariate outliers based on standardised scores. The analyses below were carried out on the remaining sample of 295, with 149 participants who received the parent version of the questionnaire and 146 who received the motorist version. Few items were missing and these were excluded listwise from analyses. Overall intention to change, and intention to change for both subgroups, was normal. Overall identity threat was positively skewed, and was dealt with as described below. 


\section{Results}

Table 2 presents the means and standard deviations of the main variables and Table 3 presents correlations between the main variables.

Table 2 Means and standard deviations of main variables

\begin{tabular}{|c|c|c|c|c|c|c|}
\hline & \multicolumn{2}{|c|}{ All $(\mathrm{N}=295)$} & \multicolumn{2}{|c|}{ Motorist $(\mathrm{N}=146)$} & \multicolumn{2}{|c|}{ Parent $(\mathrm{N}=149)$} \\
\hline & Mean & SD & Mean & SD & Mean & SD \\
\hline Resistance to change & 4.06 & 1.15 & 4.65 & 1.04 & 3.49 & .96 \\
\hline Identity threat & 2.38 & 1.26 & 2.59 & 1.43 & 2.17 & 1.03 \\
\hline Reactance & 2.69 & 1.17 & 2.93 & 1.20 & 2.46 & 1.09 \\
\hline Baseline intention to change & 2.84 & 1.53 & 2.43 & 1.34 & 3.24 & 1.60 \\
\hline Identity centrality & 4.83 & 1.35 & 4.40 & 1.53 & 5.24 & 1.00 \\
\hline Trait reactance & 3.17 & .67 & 3.24 & .66 & 3.10 & .68 \\
\hline \multicolumn{7}{|l|}{ Past behaviour: } \\
\hline Walk & 3.41 & 1.18 & 3.06 & 1.23 & 3.74 & 1.02 \\
\hline Cycle & 1.67 & 1.05 & 1.51 & .91 & 1.82 & 1.15 \\
\hline Bus & 1.96 & 1.12 & 1.83 & 1.08 & 2.09 & 1.15 \\
\hline Train & 2.03 & 1.13 & 1.97 & 1.04 & 2.09 & 1.21 \\
\hline Children walk & 3.14 & 1.56 & - & - & 3.14 & 1.56 \\
\hline Positive affect & 2.63 & .84 & 2.53 & .78 & 2.73 & .88 \\
\hline Negative affect & 1.36 & .50 & 1.30 & .46 & 1.41 & .54 \\
\hline
\end{tabular}


Table 3 Correlations between main variables

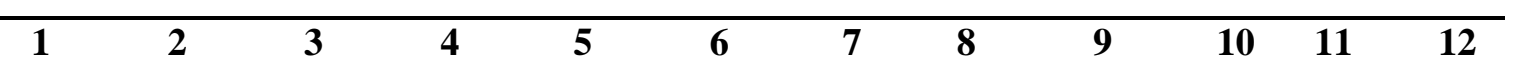

1. Age

2. Gender ${ }^{\mathrm{a}}$

.07

3. Resistance to change

$.24 * * .13 *$

4. Identity threat

$.03 \quad-.01 \quad .33 * *$

5. Reactance

$\begin{array}{llll}.06 & -.06 & .35 * * & .81 * *\end{array}$

6. Baseline intention to change

$\begin{array}{lllll}-.15 * * & -.12 * & -.37 * * & -.05 & .00\end{array}$

7. Identity centrality

$\begin{array}{llllll}-.13 * & -.02 & -.05 & .22 * * & .15 * & .01\end{array}$

8. Trait reactance

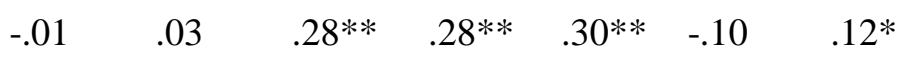

9. Past behaviour: walk $\begin{array}{llllllll}-.13 * & -.19 * * & -.45 * * & -.14 * & -.15 * * & .27 * * & .02 & -.18 * *\end{array}$

10.Past behaviour: cycle

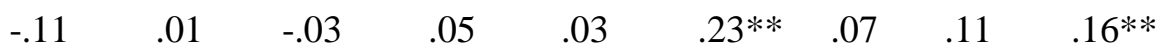

11.Past behaviour: bus

$\begin{array}{llllllllll}.05 & -.13 * & -.28 * * & -.05 & -.09 & .26 * * & .04 & -.21 * * & .30 * * & .07\end{array}$

12.Past behaviour: train

$\begin{array}{lllllllllll}-.05 & -.09 & -.17 * * & -.02 & -.05 & .18 * & .03 & -.09 & .25 * * & .04 & .37 * *\end{array}$

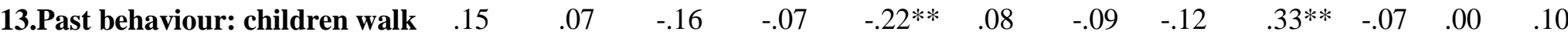

Note. ${ }^{\mathrm{a}} 1=$ female, $2=$ male. $* p<.05$, $* * p<.01$ 
The correlation of $.81(p=.00)$ between psychological reactance and identity threat suggests that these are be overlapping constructs, supporting the theoretical argument in Section 1 above. Correlations were also conducted by role identity, and showed a similarly high correlation between reactance and identity threat for both motorist $(r=.82)$ and parent $(r$ $=.80)$ groups. The overall pattern of correlations was similar, with the exception that, for the parent group, identity threat and resistance to change did not correlate significantly $(r=.15, p$ $=.07)$, whereas reactance and resistance to change were significantly correlated $(r=.19, p=$ $.02)$

As a manipulation check that the vignettes had induced threat, differentially between neutral and threat conditions, and across both motorist and parent subgroups, we conducted a mixed-design analysis of variance of identity threat with one repeated condition (threat versus neutral vignettes). Because identity threat across all participants was skewed (skew $=1.00$, SE skew $=.14)$, the variables were first transformed by calculating the square root. Inspection of the distribution graph and a smaller skew statistic $($ skew $=.54$, SE skew $=.14)$ showed an acceptably minor deviation from normality on a sample size of 295. Mean identity threat was higher for the threat vignettes, for both motorist and parent subgroups (mean for threat vignettes: motorist $=2.95$, parent $=2.47$; mean for neutral vignettes: motorist 2.39 , parent $=$ 2.15). The effect of identity threat was significant $(F(1,293)=69.01, p=.00)$, demonstrating that the vignette design had induced threat. The interaction was non-significant $(F(1,293)=$ $1.02, p=.31$ ), showing that the level of threat did not differ significantly between the motorist and the parent subgroups.

As a first test of our main hypothesis, that threat to identity would relate to resistance to change travel behaviour, we conducted a mixed-design analysis of variance of resistance to change, with threat versus neutral vignettes as the repeated condition. The mean resistance to change was higher for the threat vignettes, for both motorist (threat mean 5.28, neutral mean 
4.56) and parent (threat mean 3.86, neutral mean 3.39) subgroups (see Figure 1). The effect of threat on resistance to change was significant $(F(1,293)=50.25, p=.00 ; \mathrm{r}=.38)$ and this effect did not differ significantly between the subgroups $(F(1,293)=2.38, p=.12)$. This supports Hypotheses 1, that threat to identity is related to resistance to change.

Figure 1 Mean resistance to change for neutral versus threat condition

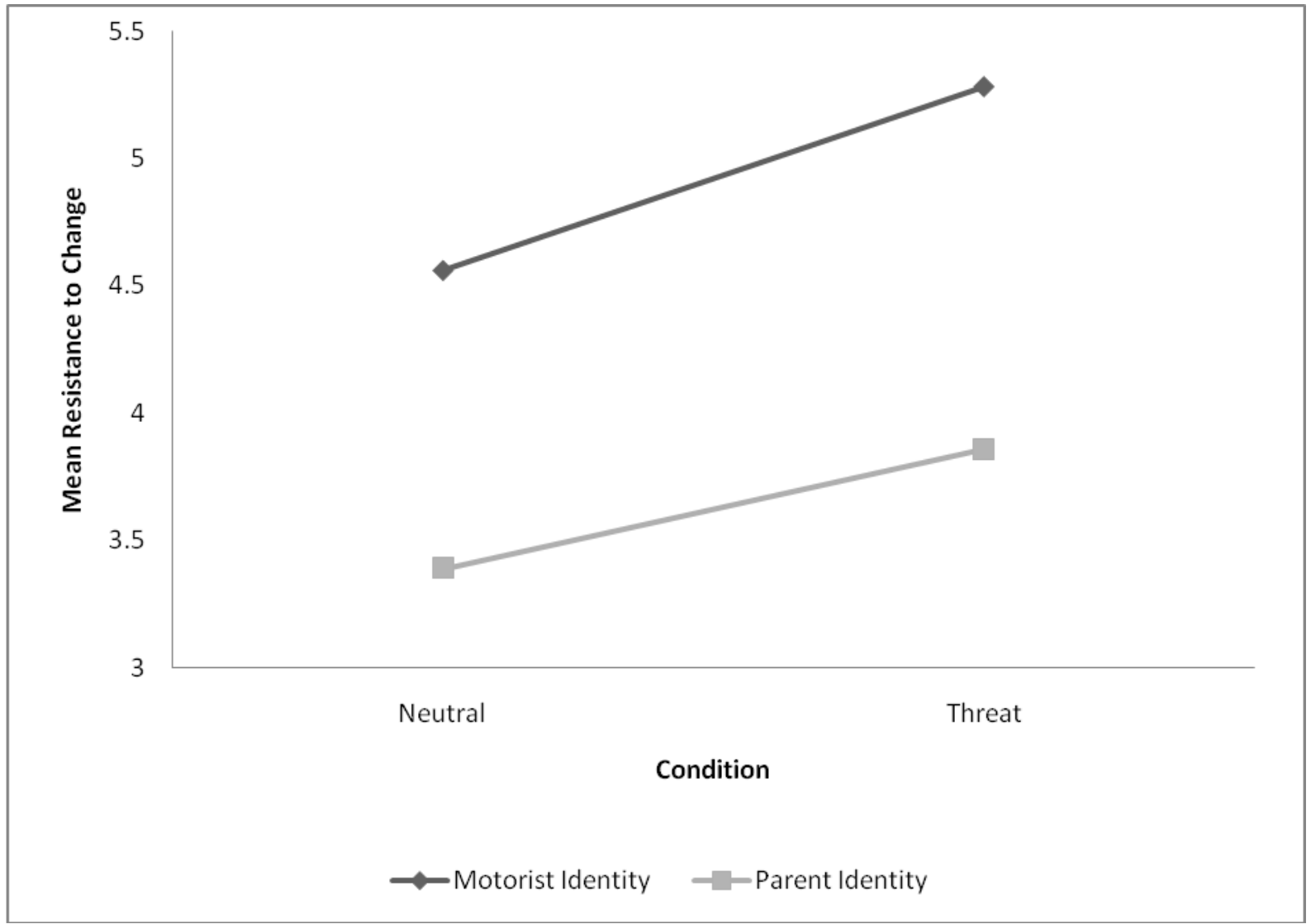

Next we wanted to assess whether the threat to identity explained the variance in resistance to change over and above other contributory factors. We therefore conducted a multiple regression, in which resistance to change travel behaviour was regressed onto identity threat, while controlling for baseline intention to change travel behaviour, past travel behaviour, trait reactance and identity centrality ${ }^{2}$. Because identity threat was positively

\footnotetext{
2 Identity salience was also measured, using two items from Callero (1985): "Being a motorist/parent is something I rarely even think about", "I really don't have any clear feelings about being a motorist/parent" (Cronbach $\alpha=.81$ for motorist identity, .82 for parent identity). However, identity centrality and identity salience demonstrated multicollinearity, thus only
} 
skewed, the variables were first transformed by taking the square root. All variables were entered simultaneously. Due to their high correlation coefficient, separate regressions were conducted for identity threat and state reactance. Table 4 presents the regression results.

The regressions supported Hypothesis 2: identity threat contributed to resistance to change travel behaviour over and above past or habitual travel mode choice. Using the test recommended by Clogg, Petkova and Haritou (1995) and Paternoster, Brame, Mazerolle and Piquero (1998) to examine whether the coefficients for identity threat in each group differed significantly, we found that the coefficients did not differ significantly, suggesting that the contribution of threat was equivalent in each group.

As expected, trait reactance and past travel mode, specifically walking, also contributed significantly. A test for mediation showed that previous behaviour (walking) partially mediated the relationship between identity centrality and resistance to change for the motorist vignettes (Sobel $\mathrm{z}=2.08$ ), but was non-significant for the parent vignettes.

Of particular interest was the difference in direction of the relationship between identity centrality and resistance to change for threat to motorist and parent identities. For threat to a motorist identity, the more central the identity as a motorist, the less likely was intention to change. In contrast, for threats to a parent identity, the more central the parent identity, the more likely was intention to change travel behaviour. A further difference between motorist and parent identities was the baseline intention to change: for the motorist group, but not the parent group, a prior intention to change increased the outcome intention to change.

identity centrality was used in the final regression. The regressions were also run with identity salience and the results followed the same pattern. 
Table 4 Regression of resistance to change onto identity threat [state reactance] and control variables ( $\beta$ values)

\section{All (N=295) Motorist subgroup $\quad$ Parent subgroup}

$$
(\mathrm{N}=146) \quad(\mathrm{N}=149)
$$

\begin{tabular}{llll}
\hline Age & $.13^{* *}\left[.13^{* *}\right]$ & $.10[.09]$ & $-.01[.01]$
\end{tabular}

Baseline intention to $\quad-.21 * * *[-.23 * * *] \quad-.37 * * *[-.37 * * *] \quad-.01[-.03]$

change

Past behaviour:

Walk

Cycle

Bus

Train

Trait reactance

Identity centrality

Identity threat

[State reactance]

$\begin{array}{lll}-.28^{* *}\left[-.28^{* *}\right] & -.21^{* *}\left[-.20^{* *}\right] & -.23^{* *}\left[-.23^{* *}\right] \\ .06[.07] & .06[.07] & .11[.11] \\ -.08[-.07] & -.18^{*}\left[-.18^{*}\right] & .07[.08] \\ .02[.03] & .04[.05] & -.07[-.07] \\ .12 *[.11 *] & -.20[-.01] & .19 *\left[.17^{*}\right] \\ -.10^{*}[-.08] & .16^{*}\left[.18^{*}\right] & -.25^{*}\left[-.25^{*}\right] \\ .26 * * *[.26 * * *] & .24 * *[.21 * *] & .17^{*}\left[.18^{*}\right]\end{array}$

Adj. $\boldsymbol{R}^{2}$

$.35[.35]$

$F(12,277)=13.73 * * *$

[13.814***]
$.45[.44]$

$F(12,132)=10.91 * * *$

$[10.60 * * *]$
$.16[.16]$

$F(12,132)=3.32 * * *$

[3.33***]

Notes: $(1) * * * p<.001, * * p<.01, * p<.05$.

(2) Gender, positive and negative affect were included and were non-significant. 
As Table 4 shows, psychological reactance and identity threat demonstrated almost identical contribution to variance in resistance to change, supporting the argument in Section 1 that reactance and identity threat are conceptually overlapping.

In a further analysis, we tested whether identity centrality moderated the relationship between identity threat and resistance to change. Resistance to change was regressed onto identity threat, identity centrality and their interaction (identity threat $\mathrm{x}$ identity centrality). All variables had been standardised. The interaction effect was non-significant, suggesting that identity centrality was not a moderator. Exploring whether this held for both motorist and parent identities, a three-step regression was conducted on standardised variables. In Step 1, independent variables were identity threat, identity centrality and identity type $(0=$ motorist, $1=$ parent). In Step 2, the three two-way interaction terms were included and Step 3 comprised the three-way interaction term (identity threat $\mathrm{x}$ identity centrality $\mathrm{x}$ identity type). Step 3 did not add significant explanation of variance, confirming that identity centrality had not moderated the relationship between identity threat and resistance to change. Two-way and three-way interactions were also calculated for psychological reactance in place of identity threat, and the findings were the same.

As identity threat was measured using threats to four identity principles (self-esteem, self-efficacy, continuity and distinctiveness), regressions were also conducted with the four single item measures as independent variables: multicollinearity was indicated, with tolerance values under 1.2 (Menard, 1995).

\section{Discussion}

The study asked 295 working parents in England, with access to private cars and public transport, to indicate their intention to change travel behaviour in response to eight transport-related vignettes. Half of the sample was presented with vignettes targeting a motorist identity, and half with vignettes targeting a parent identity. In each set of eight, four 
vignettes were designed to threaten the target identity and four were designed as neutral. Analysis of variance showed that resistance to change was greater in the threat vignettes, for both subgroups. Regression analyses demonstrated that self-identity threat predicted resistance to change, beyond the predictive power of past travel behaviour and trait psychological reactance. The relationship between threat to identity and resistance to change was significant both for a motorist identity as well as a parent identity, supporting the hypothesis that identity threat contributes to resistance to change.

The findings here add to a number of previous studies which have linked identity and behaviour. Behaviours of relevance to sustainability, including recycling (Mannetti, Pierro, \& Livi, 2004; Nigbur, Lyons, \& Uzzell, 2010), green consumerism (Sparks \& Shepherd, 1992) and a range of pro-environmental behaviours including domestic energy conservation (Whitmarsh \& O'Neill, 2010), have been shown to be influenced by conceptions of identity.

Our finding that identity threat predicts resistance to change is consistent with previous work which showed that particular types of threat may influence pro-environmental intentions. Feinberg and Willer (2011) explored just-world beliefs, Feygina, Jost and Goldsmith (2010) looked at group-based beliefs, and Vess and Arndt (2008) investigated threats to mortality and environmental concern. Although it could be argued that the concept of threat, in itself, offers explanation of behavioural responses, the application of an identity theoretical approach offers the potential to move beyond a straightforward, uni-dimensional link between threat and resistance. There is a need to explain more of the variability in behavioural reactions to threat and we suggest that identity theories, and IPT in particular, may offer explanation of the psychological processes underlying responses to threat. The concept of identity as dynamic, contextual and social raises the potential to see response to threat as complex, varied and indeed part of the development of identity and evolution of behaviour. 
We now discuss some specific findings from the results before drawing together the implications of the study for understanding influences on travel behaviour, and for utility more generally in campaigns to encourage sustainable behaviour.

As discussed in the Introduction, the relationship between psychological reactance and the processes of identity threat may be difficult to untangle: the suggestion was made that reactance in response to a threat to freedom may overlap conceptually with general threats to identity. In the findings here, the high correlation between state reactance and identity threat, and the almost identical results from regressions which included either identity threat or reactance, revealed the constructs to be empirically indistinguishable in the current data. Although it is possible that this may have resulted from conceptually overlapping measurement items, the items were generated based on different theoretical approaches in the literature, for example, freedom - 'It threatens my freedom'; self-efficacy - 'It makes me feel less competent'; continuity - 'I would have to change who I am'. A measurement artefact is not considered a likely cause but future studies should conduct measures of identity threat and reactance using different operationalisations, testing within- and between-subjects and testing within-subjects at different times.

The significant negative contribution of past travel behaviour to resistance to change, especially walking, and of previous intention to change, may relate to a physical infrastructure and journeys that facilitated walking. It can also be suggested that, since previous behaviour (walking) partially mediated the relationship between identity centrality and resistance to change for the motorist vignettes, that identity played a role. It has been argued that the relationship between past behaviour and future intentions could be explained by stable factors influencing both past and future behaviour and identity may be one such factor (Bamberg, Ajzen, \& Schmidt, 2003). The Self-Reported Habit Index (SRHI), a measure of habit strength, includes an item to tap identity (Verplanken \& Orbell, 2003). The 
findings here are consistent with these perspectives which suggest that self-identity contributes to past behaviour, as well as to current behaviour and intention.

The moderate to strong relationship of baseline intention change and resistance for the motorist group was as expected: where these participants had a prior intention to drive less, they were more likely to indicate an intention to change in response to the vignettes. The lack of relationship for the parent group is more surprising. A possible reason may be how closely connected were the threat, the role identity, the outcome behaviour of interest and the prior intention. For the motorist identity, the threat linked directly to identity-related (i.e. driving) behaviour. Both threat and driving behaviour were directly linked to the outcome of interest (i.e. changing car use), which in turn was closely linked to the baseline intention. For the parent identity however, the threat focused on behaviours, such as walking a child to school, which represent one of many possible parental behaviours, and may not be central to enactment of the identity. Likewise, the outcome behaviours, such as walking more often with a child, are only one possible type of response to threat, and a wider range of coping strategies may have been drawn on to protect a parent identity. Hence a prior intention to drive less (a specific behaviour) would not necessarily be significantly related to outcome behaviour (a range of possible behaviours) in response to threat. This would imply that the more directly an identity threat is linked to an outcome behaviour, the stronger will be the effect of threat. This tentative explanation is supported by the stronger contribution of identity threat to resistance to change for the motorist group over the parent group.

An implication that may be drawn from the contribution of walking, and of previous intention to change travel behaviour, is that early stages of encouraging more sustainable travel may be crucial. If people can be persuaded to walk sometimes, they may then be less resistant to further change. Fujii and Kitamura (2003) showed that when drivers were encouraged to take a bus for a period of time, they were more likely to travel by bus 
subsequently. From an identity perspective, occasional changes may facilitate the development of a new or modified identity. Through walking at least sometimes, individuals may begin to see themselves as 'someone who walks', and this identity then may guide subsequent behaviour.

In approaching this study, we contested that role identities could offer a domain within a larger construct of identity; based on previous theory and research (Thoits, 1992), we focussed on the two role identities of motorist and parent. We are aware that taking this position revives an earlier theoretical discussion of the relationship between domains of identity, specifically place identity and social identity (cf. Twigger-Ross \& Uzzell, 1996, p. 206). This discussion revolved around an interpretation of Proshansky et al's $(1983,1987)$ understanding of place identity which proposes that place identity is another aspect of identity comparable to social identity. Such a position is in danger of leading unhelpfully to a dualistic conception of identity in which discussion would focus on whether or not identity was more 'social' or more 'place'. As was argued in relation to place identity, we would suggest that rather than there being a separate part of identity concerned with roles, all aspects of identity will, to a greater or lesser extent, have role-related implications.

The question then arises: to what extent is the process of response to threat general for the self or specific to a role identity? If the processes of identity threat are role identityspecific, we would expect to find that centrality of the role identity influences the relationship between threat and resistance. In this case, we would anticipate a moderation effect of identity centrality on the relationship: that is, we would predict that the more central an identity, the stronger the relationship between identity threat and resistance to change. However, moderation was not demonstrated in our study. We can thus tentatively suggest that the psychological processes for dealing with threats to identity operate at the general level of the self-concept, even when threats are targeted at a particular role identity such as 
parent. This is consistent with our positioning of specific role identities as domains within the content of the self and with the theoretical propositions of IPT, which proposes general processes for coping with threat. Future research should investigate more role identities, and compare threats to specific role identities and more general identity threat.

The application of identity theory to resistance to change travel behaviour, we suggest, underlines the importance of addressing identity as a factor in behaviour change and future intervention strategies for sustainability. We further suggest that the findings from the current study, and its theoretical basis, offer explanation of some of the psychological processes underlying responses to threat. While the findings may suggest reasons why change may be difficult to initiate (i.e., when threats to identity lead to resistance), they also suggest ways of moving beyond resistance. As such, looking at resistance to change through the prism of Identity Process Theory extends previous research on threat and resistance. Of the many implications for application of the findings, two are briefly outlined: the first relates to how approaches aimed changing behaviour towards greater sustainability may trigger resistance; the second suggests ways in which such behaviour may be encouraged.

Campaigns to encourage more sustainable behaviour may undermine the self-efficacy principle. The principle suggests that individuals need to feel competent and in control of their lives and context. Enforced change, through legislation for example, may undermine individuals' sense of self-efficacy, and may result in resistance. However, Identity Process Theory also suggests that threat may bring about acceptance and change. The current study did not investigate this possibility, having sought to establish the basic relationships between threats to identity, as defined by the theory, and resistance to change. It remains for future research to explore under what conditions change rather than resistance may be initiated. Drawing more generally on the findings, particularly the relationships between identity centrality and threat to the parent role identity, it can be suggested that role identities such as 
parent, member of the local community (Gardner \& Abraham, 2007), and perhaps 'good citizen' or 'person of faith' may offer potential for change rather than resistance. Some earlier studies appeared to link specific values to role identities, for example the "green consumer" (Sparks \& Shepherd, 1992). This may point to ways in which role identities could be used constructively to change behaviour. For instance, role identities which may encourage sustainable behaviours - the green commuter, the energy-efficient motorist, the frugal householder - could be promulgated.

Some limitations may be noted in the current research. As an exploratory and single study, the findings should be considered tentative until verified by additional research. Although patterns of responses to the vignettes based on their order were not in evidence, a stronger design would have counterbalanced presentation of the vignettes. A further limitation was the necessity to, in part, de-contextualise the identities investigated. However, identities develop and are maintained within social and structural contexts (Christie, 2010; Uzzell, 2010) and further research is needed to explore how contexts influence the experience of identity threat. The study focused primarily on singular identities. More work is needed on the implications of multiple role identities, in particular the possibility that threat to one role identity may be compensated by recourse to another or 'spillover' from one role identity to another (Haar \& Bardoel, 2008). Finally, the current study was limited to participants who earned at or above the national average income, and were working parents. Identities and behaviours may relate to socioeconomic class or income: future research should explore if identity processes operate in a similar way across all income levels, for different sociodemographic groups and across ethnicities.

In summary, the study demonstrated that self-identity threat contributes to resistance to change travel behaviour. Self-identity threat, as explicated by Identity Process Theory, triggers psychological coping strategies, and of these, deflection strategies may account for 
resistance to change. The findings extend previous work on threat, reactance and resistance and the results suggest rich avenues for future research on the theoretical and empirical implications of the relationship of role identities and sustainable behaviours. 


\section{References}

Aarts, H., Verplanken, B., \& van Knippenberg, A. (1998). Predicting behavior from actions in the past: Repeated decision making or a matter of habit? Journal of Applied Social Psychology, 28(15), 1355-1374.

Abrams, D. M. A. (1988). Comments on the motivational status of self-esteem in social identity and intergroup discrimination. European Journal of Social Psychology, 18(4), $317-334$

Ajzen, I. (1985). From intentions to actions: A theory of planned behavior. In J. Kuhland \& J. Beckman (Eds.), Action-control: from cognitions to behavior (pp. 11-39). Heidelberg: Springer.

Ajzen, I. (1991). The theory of planned behavior. Organizational Behavior and Human Decision Processes, 50(2), 179-211.

Ajzen, I., \& Fishbein, M. (1980). Understanding attitudes and predicting social behavior. Englewood Cliffs, NJ: Prentice Hall.

Albarracin, D., Durantini, M. R., Earl, A., Gunnoe, J. B., \& Leeper, J. (2008). Beyond the most willing audiences: A meta-intervention to increase exposure to HIV-prevention programs by vulnerable populations. Health Psychology, 27(5), 638-644.

Anable, J. (2005). 'Complacent car addicts' or 'Aspiring environmentalists'? Identifying travel behaviour segments using attitude theory. Transport Policy, 12, 65-78.

Bamberg, S., Ajzen, I., \& Schmidt, P. (2003). Choice of travel mode in the theory of planned behavior: The roles of past behavior, habit, and reasoned action. Basic \& Applied Social Psychology, 25(3), 175.

Bovey, W. H., \& Hede, A. (2001). Resistance to organizational change: The role of defence mechanisms. Journal of Managerial Psychology, 16(7), 534-548.

Breakwell, G. M. (1986). Coping with threatened identities. London: Methuen. 
Breakwell, G. M. (1988). Strategies adopted when identity is threatened. Revue Internationale de Psychologie Sociale, 1, 189-203.

Brehm, J. W. (1966). A theory of psychological reactance. New York: Academic Press.

Brehm, S. S., \& Brehm, J. W. (1981). Psychological reactance: A theory of freedom and control. London: Academic Press.

Callero, P. L. (1985). Role-identity salience. Social Psychology Quarterly, 48(3), 203-215.

Carrington, D. (2011). Public belief in climate change weathers storm, poll shows. The Guardian. Retrieved 22/2/2011, from www.guardian.co.uk/environment/2011/jan/31/public-belief-climate-change

Christie, I. (2010). Foreword. In M. Peters, S. Fudge \& T. Jackson (Eds.), Low carbon communities: Imaginative approaches to combating climate change locally (pp. xivxviii). Cheltenham, UK: Edward Elgar.

Chung, S. S., \& Leung, M. M. Y. (2007). The value-action gap in waste recycling: The case of undergraduates in Hong Kong. Environmental Management, 40, 603-612.

Clogg, C. C., Petkova, E., \& Haritou, A. (1995). Statistical methods for comparing regression coefficients between models. American Journal of Sociology, 100, 1261-1293.

Dent, E. B., \& Goldberg, S. G. (1999). Challenging 'resistance to change'. Journal of Applied Behavioral Science, 35(1), 25-41.

DfT. (2009). Transport Statistics for Great Britain: 2009 edition. Retrieved 5/10/2010, from www.dft.gov.uk/pgr/statistics/datatablespublications/2009edition

Druckman, A., \& Jackson, T. (2009). Mapping our carbon responsibilities: More key results from the Surrey Environmental Lifestyle Mapping Framework (SELMA). RESOLVE Working Paper Series 02-09. Guildford:University of Surrey.

Emmons, R. A. (1986). Personal strivings: An approach to personality and subjective wellbeing. Journal of Personality and Social Psychology, 51, 1058-1068. 
Falomir, J. M., \& Invernizzi, F. (1999). The role of social influence and smoker identity in resistance to smoking cessation. Swiss Journal of Psychology/Schweizerische Zeitschrift für Psychologie/Revue Suisse de Psychologie, 58(2), 73-84.

Feinberg, M., \& Willer, R. (2011). Apocalypse soon? Dire messages reduce belief in global warming by contradicting just-world beliefs. Psychological Science, 22(1), 34-38.

Feygina, I., Jost, J. T., \& Goldsmith, R. E. (2010). System justification, the denial of global warming, and the possibility of "system-sanctioned change". Personality and Social Psychology Bulletin, 36(3), 326-338.

Fishbein, M., \& Ajzen, I. (1975). Belief, attitude, intention and behavior: An introduction to theory and research. Reading, MA: Addison-Wesley.

Flynn, R., Bellaby, P., \& Ricci, M. (2009). The 'value-action gap' in public attitudes towards sustainable energy: The case of hydrogen energy. Sociological Review, 57, 159-180.

Ford, J. D., \& Ford, L. W. (2010). Stop blaming resistance to change and start using it. Organizational Dynamics, 39(1), 24-36.

Fujii, S., \& Kitamura, R. (2003). What does a one-month free bus ticket do to habitual drivers? An experimental analysis of habit and attitude change. Transportation, 30(1), $81-95$.

Gardner, B., \& Abraham, C. (2007). What drives car use? A grounded theory analysis of commuters' reasons for driving. Transportation Research Part F: Traffic Psychology and Behaviour, 10(3), 187-200.

Gärling, T., \& Axhausen, K. W. (2003). Introduction: Habitual travel choice. Transportation, $30,1-11$.

GinerSorolla, R., \& Chaiken, S. (1997). Selective use of heuristic and systematic processing under defense motivation. Personality and Social Psychology Bulletin, 23(1), 84-97. 
Gray, D., Amos, A., \& Currie, C. (1997). Decoding the image of consumption, young people, magazines and smoking: An exploration of theoretical and methodological issues. Health Education Research, 12(4), 505-517.

Haar, J. M., \& Bardoel, E. A. (2008). Positive spillover from the work-family interface: A study of Australian employees. Asia Pacific Journal of Human Resources, 46(3), 275287.

Hansen, J., Winzeler, S., \& Topolinski, S. (2010). When death makes you smoke: A terror management perspective on the effectiveness of cigarette on-pack warnings. Journal of Experimental Social Psychology, 46(1), 226-228.

Hellman, C. M., \& McMillin, W. L. (1997). The relationship between psychological reactance and self-esteem. The Journal of Social Psychology, 137(1), 135-138.

Hong, S.-M., \& Faedda, S. (1996). Refinement of the Hong Psychological Reactance Scale. Educational and Psychological Measurement, 56(1), 173-182.

Invernizzi, F., Falomir-Pichastor, J. M., Munoz-Rojas, L., \& Mugny, G. (2003). Social influence in personally relevant contexts: The respect attributed to the source as a factor increasing smokers' intention to quit smoking. Journal of Applied Social Psychology, 33(9), 1818-1836.

IPCC. (2007). Contribution of Working Groups I, II and III to the Fourth Assessment Report of the Intergovernmental Panel on Climate Change. [Core Writing Team, Pachauri, R.K and Reisinger, A. (eds.)]. . Geneva, Switzerland: IPCC.

Liberman, A., \& Chaiken, S. (1992). Defensive processing of personally relevant health messages. Personality and Social Psychology Bulletin, 18, 669-679.

Mannetti, L., Pierro, A., \& Livi, S. (2004). Recycling: Planned and self-expressive behaviour. Journal of Environmental Psychology, 24(2), 227-236.

Maslow, A. (1943). A theory of human motivation. Psychological Review, 50, 370-396. 
McAdams, D. P. (1995). Can personality change? Levels of stability and growth in personality across the life space. In T.F. Heatherton \& J.L. Weinberger (Eds.). Can personality change? (pp. 299-314). Washington, DC: American Psychological Association.

Menard, S. (1995). Applied logistic regression analysis. Sage university paper series on quantitative analysis in the social science. 07-106. Thousand Oaks, CA: Sage.

Murtagh, N., Gatersleben, B., \& Uzzell, D. (2012). Multiple identities and travel mode choice for regular journeys. Transportation Research Part $F$, in press.

Nigbur, D., Lyons, E., \& Uzzell, D. (2010). Attitudes, norms, identity and environmental behaviour: Using an expanded theory of planned behaviour to predict participation in a kerbside recycling programme. British Journal of Social Psychology, 49(2), 259284.

Nuttbrock, L., \& Freudiger, P. (1991). Identity salience and motherhood: A test of Stryker's theory. Social Psychology Quarterly, 54(2), 146-157.

ONS. (2010). Social Trends. Retrieved 5/8/2010, from http://www.statistics.gov.uk/cci/nugget.asp?id=2449

Oreg, S. (2003). Resistance to change: Developing an individual difference measure. Journal of Applied Social Psychology, 88, 680-693.

Ouellette, J. A., \& Wood, W. (1998). Habit and intention in everyday life: The multiple processes by which past behavior predicts future behavior. Psychological Bulletin, 124(1), 54-74.

Oyserman, D., Fryberg, S. A., \& Yoder, N. (2007). Identity-based motivation and health. Journal of Personality and Social Psychology, 93(6), 1011-1027.

Paternoster, R., Brame, R., Mazerolle, P., \& Piquero, A. (1998). Using the correct statistical test for the equality of regression coefficients. Criminology, 36(4), 859-866. 
Pavey, L., \& Sparks, P. (2009). Reactance, autonomy and paths to persuasion: Examining perceptions of threats to freedom and informational value. Motivation and Emotion, 33(3), 277-290.

Proshansky, H. M., \& Fabian, A. (1987). The development of place identity in the child. In C. S. Weinstein \& T. G. David (Eds.), Spaces for Children (pp. 21-40). New York: Plenum Press.

Proshansky, H. M., Fabian, A. K., \& Kaminoff, R. (1983). Place identity: physical world socialisation of the self. Journal of Environmental Psychology, 3, 57-83.

Rogers, C. R. (1965). Interpersonal relationships: USA 2000. Journal of Applied Behavioral Science, 4(3), 265-280.

Rosenberg, M. (1979). Conceiving the self. New York: Basic Books.

Ryan, R. M., \& Deci, E. L. (2000). Self-determination theory and facilitation of intrinsic motivation, social development and well-being. American Psychologist, 55(1), 68-78.

Schwartz, S. H. (1992). Universals in the content and structure of values - theoretical advances and empirical tests in 20 countries. Advances in Experimental Social Psychology, 25, 1-65.

Sedikides, C., \& Strube, M. J. (1997). Self-evaluation: To thine own self be good, to thine own self be sure, to thine own self be true and to thine own self be better. Advances in Experimental Social Psychology, 29, 209-269.

Sheldon, K. M., Elliot, A. J., Kim, Y., \& Kasser, T. (2001). What is satisfying about satisfying events? Testing 10 candidate psychological needs. Journal of Personality and Social Psychology, 80(2), 325-339.

Sparks, P., \& Guthrie, C. A. (1998). Self-identity and the theory of planned behaviour: A useful addition or an unhelpful artifice? Journal of Applied Social Psychology, 28(15), 1393-1410. 
Sparks, P., \& Shepherd, R. (1992). Self-identity and the theory of planned behavior: Assessing the role of identification with "Green Consumerism". Social Psychology Quarterly, 55(4), 388-399.

Spence, A., Venables, D., Pidgeon, N., Poortinga, W., \& Demski, C. (2010). Public perceptions of climate change and energy futures in Britain: Summary findings of a survey conducted in January - March 2010. Cardiff: School of Psychology, University of Cardiff.

Stoll-Kleemann, S., O'Riordan, R., \& Jaeger, C. C. (2001). The psychology of denial concerning climate mitigation measures: Evidence from Swiss focus groups. Global Environment, 11, 107-117.

Stryker, S. (1987). Identity theory: developments and extensions. In K. Yardley \& R. Honess (Eds.), Self and identity: Psychosocial perspectives (pp. 89-103). Oxford: John Wiley and Sons.

Tesser, A., \& Cornell, D. P. (1991). On the confluence of self processes. Journal of Experimental Social Psychology, 27(6), 501-526.

Thoits, P. A. (1992). Identity structures and psychological well-being: Gender and marital status comparisons. Social Psychology Quarterly, 55, 236-256.

Twigger-Ross, C., \& Uzzell, D. L. (1996). Place identity and place attachment. Journal of Environmental Psychology, 16(2), 205-220.

Uzzell, D. (2010). Collective solutions to a global problem. The Psychologist, 23, 880-883.

Verplanken, H., Aarts, B., \& Van Knippenberg, A. (1997). Habit, information acquisition, and the process of making travel mode choices. European Journal of Social Psychology, 27(5), 539.

Verplanken, B., \& Orbell, S. (2003). Reflections on past behavior: A self-report index of habit strength. Journal of Applied Social Psychology, 33(6), 1313-1330. 
Vess, M., \& Arndt, J. (2008). The nature of death and the death of nature: The impact of mortality salience on environmental concern. Journal of Research in Personality, 42(5), 1376-1380.

Vignoles, V. L., Chryssochoou, X., \& Breakwell, G. M. (2002). Evaluating models of identity motivation: Self-esteem is not the whole story. Self and Identity, 1(3), 201218.

Vignoles, V. L., Regalia, C., Manzi, C., Golledge, J., \& Scabini, E. (2006). Beyond selfesteem: Influence of multiple motives on identity construction. Journal of Personality and Social Psychology, 90(2), 308-333.

Watson, D., Clark, L. A., \& Tellegen, A. (1988). Development and validation of brief measures of positive and negative affect - the PANAS scales. Journal of Personality and Social Psychology, 54(6), 1063-1070.

Whitmarsh, L. (2009). Behavioural responses to climate change: Asymmetry of intentions and impacts. Journal of Environmental Psychology, 29(1), 13-23.

Whitmarsh, L., \& O'Neill, S. (2010). Green identity, green living? The role of proenvironmental self-identity in determining consistency across diverse proenvironmental behaviours. Journal of Environmental Psychology, 30(3), 305-314. 


\section{Appendix Sample vignettes}

[Italics added to show targeting of role identity]

\section{Threat vignette: Motorist}

You live about 10km (6 miles) from your work. Although there is a direct bus service, you normally drive. In order to cut local traffic, a local 'green' group has started a new initiative. They are targeting motorists as the source of the problem and assume that all drivers are oblivious to the impact of cars. The group are surveying rush-hour drivers and asking about home address and distance travelled to work. A letter will then be sent to all motorists, explaining in very simple terms the problems that drivers are causing, and giving instructions on alternatives to driving. For example, drivers who live between 3 and 10km from work would be told they should cycle, and drivers living further away on a bus route would be told they should take public transport.

\section{Threat vignette: Parent}

You live quite close to your children's school and you usually drive there. The local council has produced research showing that children who are driven to the school gates are likely to perform worse in academic tests conducted in the morning, than children who walk. They intend to use this information, in conjunction with the results of survey data about how children travel to school, to write to parents who drive their children to school. The letter to parents would point out how driving your child to school is bad for the child's academic achievement, and instruct you on ways of better parenting with respect to travel to school.

\section{Neutral vignette}

You are a regular car driver, using the car to go shopping, to the gym and to meet friends locally in the evenings and at weekends. As part of meeting its climate targets, the government is considering schemes to encourage more people to use public transport. One such scheme is the "frequent passenger". This would operate in a similar fashion to "frequent flyer" programmes. Every use of public transport would earn points for the individual. Points could be exchanged for vouchers for shopping, restaurants, theatres and attractions, or money off future journeys by tram, bus or train. 